\title{
Separators in Orthodontics: A Review
}

\author{
Dr Suchita Tarvade (Daokar) \\ Prof, Dept of Orthodontics, CSMSS Dental College, Aurangabad, India \\ Correspondence: Dr Suchita Tarvade (Daokar); Email: suchitadaokar@gmail.com
}

\section{ABSTRACT}

Placement of bands on the posterior teeth are preferred to bonding due to heavy masticatory forces. Placement of bands needs interdental separation of $0.2 \mathrm{~mm}$, which requires prior placement of separators for couple of days. Various types of separators are commercially available in the market, with their own advantages and disadvantages. A scientific review of this most useful armamentarium in orthodontics was lacking and therefore a search was undertaken to gather information on separators. This article deals with various aspects of separators in detail

\section{INTRODUCTION}

Placement of bands in posterior region is preferred over bonding, as posterior teeth experience larger masticatory force than the anteriors. The average periodontal ligament (PDL) space is $0.25 \mathrm{~mm}$ and placement of a $0.16 \mathrm{~mm}$ thick metal band without proper tooth separation can lead to contraction of the alveolar bone which in turn shall produce hyalinization areas in the PDL' and evoke pain. ${ }^{2,3}$

Separation of teeth to create interproximal space is the first step in banding. ${ }^{4}$ It is important to remember that, as separator placement is the done in the first appointment a painless procedure proves to be an important step in building trust with the patient. Separation is an orthodontic procedure aiming at slightly loosening the tight interproximal contacts between teeth to create space for the fitting of orthodontic brands by forcing or wedging the teeth apart usually for one week. ${ }^{5}$ Orthodontic separators though used daily in orthodontic practice is the least researched auxiliary till date.

\section{History of Separators}

In 1907, Angle first discussed the need to separate the teeth for placement of bands. He used brass wire for this purpose. The brass wire was passed under the contact point, then carried on over the contact. The two ends of the wire were then tightly twisted together and tucked into the interdental area. He stated "Such a ligature will not give annoyance from displacement so liable in the use of wedges, and if worn a few hours, it will be found that ample space has been gained for the accommodation of the band." 6

In 1921, Calvin Case advocated the use of separating tape, which was flax waxed tape wrapped around the contact. He said that the tape should be left on for only 24 hours and then changed if separation was insufficient.?
Oliver $^{8}$ explained the reasons for separation in the following manner.

- $\quad$ To reduce physical pain to the lowest possible degree.

- To prevent injury to the tooth structure from excess pressure.

- To reduce physical and mental tension of the patient by having the band material conveniently carried to place.

- To prevent distortion of the band material by not having to force it unduly to position during band construction.

Graber ${ }^{9}$ suggested that duration of the placement of separation should be as per the personal preference. However, no mention was made about the length of time the separators are to be placed or amount of space that has to be gained.

Thurow ${ }^{10}$ was the first to mention rubber separators. He considered its use when rapid separation is required. He suggested to remove these separators as early as possible. He suggested that the action of these separators is not selflimiting and its extended placement should be avoided.

The Begg technique introduced separating springs. Anderson used it for rapid separation within few hours. Begg used these separators for few days. Begg suggested that the springs should be left in place till the discomfort ceases; whereas they should not be left for so long that they fall off on their own."

The initial elastomer used was natural rubber (or caoutchouc) collected from the sap of Heveabrasiliensis tree. Elastomer is a general term that includes macromolecular material, which after deformation returns to its original dimensions. ${ }^{12}$ The natural rubber was of less use until the introduction of the process of vulcanization. The process led to the formation of cross-links in the individual polymer molecules, converting a viscous entanglement molecules with long chains in threedimensional elastic network; these molecules at various points 


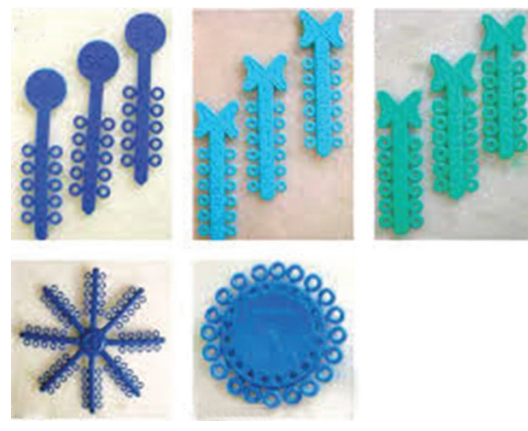

Figure 1: Elastomeric separators

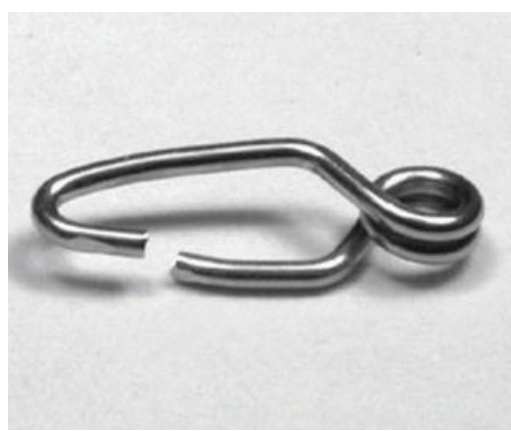

Figure 2: Kesling spring separators

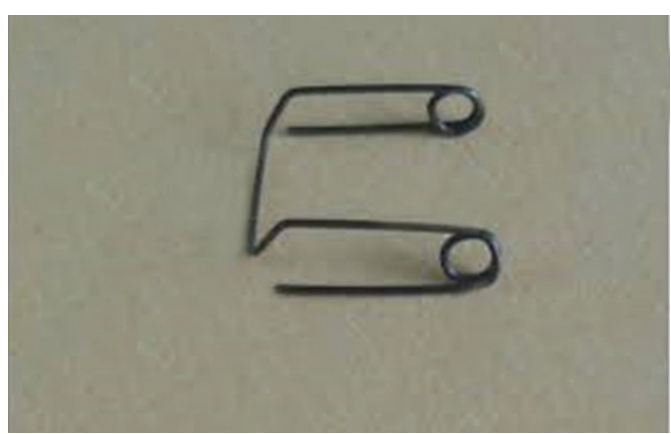

Figure 3: Kansal separator along the chain with proportional resistance to the amount of bonds. ${ }^{13,14}$

The advancement of elastomer enhanced its use in orthodontic products. Subsequently, 1990's was the year of ring seperator. The safe-T separator was a modification of elastomeric separator. Simultaneously there was introduction of various alloys in the field of dentistry. Orthodontic practice also witnessed the use of such alloys. Nickel titanium spring were introduced in the form of NEET springs by Donald McGann in 1991. ${ }^{15}$ Brosius and Sim introduced rectangular wire separator using the same principle in $1994 .{ }^{16}$

The most recent separator is Kansal separator introduced by Kansal in 2012. It is a self-secured two-in-one separator of an advantage of no dislodgement; carrying out separation on both mesial and distal aspects simulatenously. ${ }^{17}$

\section{Ideal requirements of separators}

The separator should provide adequate separation for proper band fitting and yet comfortable to the patient. It should be easy to insert in tight contacts without breakage during the insertion. It Should not dislodge while chewing food and remain till it is removed by the orthodontist. ${ }^{18,19}$ It should be autoclavable and hygienic; and should not make teeth sensitive to band seating pressure.

\section{Uses of separators}

- Separation of teeth for placement of bands

- Separation of teeth for stripping purpose

- To secure lingual retainer wire ${ }^{20}$

- To correct ectopic first permanent molars

- To correct partially impacted second or third molars 21,22

- To aid in detection of proximal caries

- Separation of teeth for proximal restorations

- To aid in the relief of bruxism and TMJ symptoms $s^{23}$

\section{Classification of separators}

1. Based on area of application

- Anterior

- Posterior

2. Based on the composition of separator

- Brass wire

- 20 gauge (for posterior teeth)

- 26 gauge (for anterior teeth)
- "C" separator (0.032"/0.81 mm)

- Stainless steel separator

- Kesling separator

- Depending on the SS (Australian) wire used : 0.016 ", 0.018 ", $0.020 "$

- Depending on the length: Short, Medium, Long, Extra long

- Kansal separator

- Nickel Titanium separators

- Elastomeric separators

- Elastic module/ Donut separators

- $1.5 \mathrm{~mm}$ inner diameter (for anterior)

- $2.1 \mathrm{~mm}$ inner diameter (for posterior)

- Dumb-bell separator

- Safe T separator

\section{Brass wire separator}

Soft brass wires of $0.5 \mathrm{~mm}$ (22 gauge) for anterior teeth and 0.6 $\mathrm{mm}$ (26 gauge) for posterior teeth are used for the separation of teeth. It is also known as pigtail separator. ${ }^{24}$

It is passed around the tooth contact and the ends are twisted tightly together using Mathieu pliers or hemostat. The end is made short (about $3 \mathrm{~mm}$ ) and then tucked between the teeth. The separating force created is based on the patient's response or clinician's experience.

These separators are easy to place as no special instrument is required for its placement and removal. However they have poor patient acceptance as they may irritate the soft tissue.

\section{Dumb-bell shaped separator}

Dumb-bell shaped (Mexican) elastic separator is dumb-bell in shape. This type of separator resembles a wide rubber band with thick rolled edges. They are obtained in strips and cut to size by the operator to accommodate various teeth. It is stretched and passed through the contacts between adjacent teeth. These separators are used for carrying out rapid separation. They are recommended to be placed 30 minutes before band fitting, but can be painful to the patient. Special pliers are not required for its placement. ${ }^{25}$

\section{Elastic ring separator (Donut separator)}

Small elastic rings made up of polyurethane are used for separation. Rings of varying thickness are placed around the 
interproximal contact point to create spaces between two adjacent teeth for banding procedure (Figure 1). They are of two types; viz rounded and with edges.

It is grasped in separator placing pliers then stretched and placed interdentally to separate the teeth, which takes about seven days. Elastic ring separators fit snugly in the interdental region and are the most comfortable to the patient. However, they can cause problems if lost into the interproximal space; thus their position and number should be noted in the chart at the time of placement and the area should be thoroughly inspected in case of missing separator during the banding appointment.

\section{Kesling separator}

Kesling metallic ring separator is a spring made up of 0.016 round Australian wire. It comprises of coil/helix, occlusal arm, gingival arm, retentive arm (Figure 2). It can be made by using Weingart, light wire or bird beak pliers. It is grasped with pliers and then placed in such a way that coil part of separator should be on buccal side. It brings about separation for banding in about two days.

It is commercially available in four sizes: short, medium, long and extra-long; depending upon the length of the arm.

Kesling separators create interdental space faster as compared to other types of separators and are easily tolerated by the patient. However, it can be dislodged and can cause tissue damage.

\section{"C" separator}

These are preformed brass wire separators of " $C$ " shape made up of $0.81 \mathrm{~mm}(0.032$ "). They are available in four lengths: short, medium, long and extra long. They are placed around contact areas of posterior teeth to maintain space prior to band placement.

\section{Orthodontic spacing spring}

Brosius and $\operatorname{Sim}^{16}$ devised spring separator from a pre-curved rectangular cross-section wire with blunted ends, preferably through the formation of loops. It is like "C" separator with the blunt ends going interdentally gingivally and the bridge crossing the inter-dental space occlusally.

\section{NiTi spring separator}

Donald Mcgann ${ }^{26}$ in 1991 created NEET spring separator with 0.018 " NiTi wire consisting of two vertical legs. The straighter vertical leg was hooked slightly at the end for easy engagement in the lingual embrasure. The opposing vertical leg was angled towards the center for engagement in the buccal embrasure. The spring was placed by engaging the straighter vertical leg with Weingart pliers, inserting the hook into the lingual embrasure, and stretching the spring over the contact until other vertical leg seats fully in the buccal embrasure.

\section{Safe-T separator}

These are ring separators with additional knob on either side of each ring. They extend beyond the interproximal area over the gingiva thus preventing the separator from submerging into the sub-gingival area. They are available in two designs: viz standard (purple) and slim (blue). ${ }^{26}$ The slim separator is thinner with less force requiring only minimal space as in anterior region.

\section{Kansal separator}

It is also known as "2-in-1" self-secured orthodontic spring separator (Figure 3). It is a single separator which separates both mesial and distal aspects of tooth simultaneously, individually, yet efficiently. It has a self-locking connecting bar for prevention of premature dislodgement of the separator. ${ }^{17}$

This separator works on the principle of double helix torsion spring which consists of a right hand and left hand round spring coil sections which are connected together, and work in parallel. When the separator is engaged, the spring coil generates force in predetermined direction. Some components of the force applied by the spring assembly (mesial/distal) are counter-balanced by each other and the resultant force in lateral (horizontal) direction pushes the two adjacent teeth such that the space is created between the mesial and distal surfaces of the desired teeth. The spring assembly produces forces in two ways; i.e. wedging action and lateral action of spring assembly.

Kansal separators are the most beneficial to the patient as they greatly reduce patient appointments, are highly comfortable, cause no gum swelling and reduced pain.

\section{Pain associated with separators}

Ngan et $\mathrm{a}^{27}$ and Bondemark ${ }^{28}$ studied response of pain after separator placement and concluded that the discomfort usually starts after four hours of separator placement, and is highest in next 24 hours. It then starts subsiding for next 5-7 days. It is least on seventh day. According to Furstman and Bernik; periodontal pain is caused by the process of pressure, ischemia, inflammation, and edema. ${ }^{29}$

Two types of painful response after orthodontic force application have been reported. One is initial response due to compression and another is delayed response due to hyperalgaesia of periodontal ligament, which is related to prostaglandin-E (PGE's) which make the PDL sensitive to released halogens such as histamine, bradykinin, serotonin, and substance-P. Other mediators reported are encephalin, dopamine, glycine, glutamate gamma-amino butyric acid, leukotrienes and cytokines. ${ }^{30}$

\section{Assessment of amount of separation}

Hoffmann ${ }^{23}$ tested the efficacy of four types of separators viz: brass wire, separating springs, latex elastics and plastic elastics 
in 20 patients for first, third and seventh days. He concluded that latex elastics produced most separation on all recorded days as compared to others.

Cureton and $\mathrm{Bice}^{31}$ compared separation among elastomeric separators, NEET and TP springs. They found elastomeric separators were more reliable than others. Elastomeric separators produced separation of $0.312 \mathrm{~mm}$ between 6/7, NEET springs produced a separation of $0.337 \mathrm{~mm}$ between $5 / 6$ and TP spring produced separation $0.273 \mathrm{~mm}$. Least separation was seen with brass separator i.e. $0.234 \mathrm{~mm}$ between $5 / 6$ and 0.223 between $6 / 7$.
McGann ${ }^{15}$ observed a mean separation of 0.008 " with NiTi springs, 0.009 " with TP springs and slightly less separation with elastomeric separators.

Bondemark et $\mathrm{a}^{28}$ obtained the mean separation of $0.3 \mathrm{~mm}$ from spring type and $0.4 \mathrm{~mm}$ from elastomeric separators and they concluded that the separation effect of two separators was clinically equivalent.

\section{REFERENCES}

1. VonBohl M, Maltha JC, VonDen Hoff JW, Kuijpers-Jagtman AM. Focal hyalinization during experimental tooth movement in beagle dogs. Am J Orthod Dentofacial Orthop. 2004; 125:615-23.

2. Sodeyama T, Maeda T, Takano Y, Hara K. Responses of periodontal nerve terminals to experimentally induced occlusal trauma in rat molars: An immunohistochemical study using PGP 9.5 antibody. J Periodontal Res. 1996; 31:235-48.

3. Ogawa T, Ishii N, Toda K, Soma K. Changes in response properties of periodontal mechaoreceptors during tooth movement in rats. J Med Dent Sci. 2002; 49:95-101.

4. Proffit RW, Fields WH, Sarver MD. Contemporary orthodontics, 4ty ed, Mosby Company. 2007; 41 1-3.

5. Daskalogiannakis J. Glossary of orthodontic terms. Quintessence Publishing Co. Inc, 2000; 244.

6. Angle EH. Treatment of malocclusion of the teeth. Philadelphia, 1907; SS White Dental Mfg Co.

7. Case CS. A practical treatise on the techniques and principles of dental orthopedia and prosthetic correction of cleft palate. Chicago, 1921, C. 8. Case Co.

8. Oliver OA. Labio-lingual technique. St. Louis, 1940; CV Mosby Co.

9. Graber T M. Orthodontic principles \& practice. 2001; WB Saunders Co.

10. Thurow Raymond C. Edgewise orthodontics. St. Louis, 1966; CV Mosby Co.

11. Anderson GM. Practical orthodontics. St.Louis, 1960; CV Mosby Co.

12. Baty DL, Storie DJ, conFrauhonfer JA. Synthetic elastomeric chains: A literature review. Am J Orthod Dentofacial Orthop. 1994; 105(6):53642.

13. Sardea A, Mateus E. Matthew E. Dicionario escolar de quimica. School dictionary of chemistry. Sao Paulo: Atica; 1981. Stern HJ. History. In: Blow CM. Rubber technology and manufacture. London: Newnes- Butterworths; 1975. Chapter 1.

14. Oliver OA. Labio-lingual technique, St. Louis, 1940; C.V. Mosby Co.

15. McGann BD. A Nickel Titanium separating spring. J Clin Orthod. 1991; 25:5:315-8.

16. Brosius DJ, Sim JM. United States Patent number. 5,314,331; 1994.

17. Kansal S, Singh G, Kumar P, Kire K: A self-secured spring separator2012; J Clin Orthod: XLM (12): 747-8,

18. Cerny R. Jumbo separators. J Clin Orthod. 2003; 37(1):33-5.

19. Mintz AH. Buccal separators for relief of TMJ pain and symptoms. Angle Orthod. 1988: 58(4):351-6.

20. Dragiff AD. Table clinic separators. J Clin Orthod. 1969; 664-71.

21. Hoffmann WE. A study of four types of separators. Am. J. Orthod Dentofacial Orthop. 1972; 62:67-73.

22. Hattarki RS, Keluskar KM. Securing a lingual retainer wire with orthodontic separators. J. Clin Orthod. 2012; 46(1):41.

23. Hirayama K, Chow MH. Correcting ectopic first permanent molars with metal or elastic separators. Pediatr Dent. 1992; 14(5):342-4.

24. Phulari B. Orthodontic principles and practice. Jaypee publication. 2011, pg 403.

25. Nair SS, Mailankody J, Sreehari N. Orthodontic separators, Kerala Dent J. 201 1; 34:1 (Suppl):148-151.

26. Singh G. Seperators in Orthodontics. Pathway to perfect. 18th PG students convention. 2014, pg 60-64

27. Ngan P, Kess B, Wilson S. Perception of discomfort by patients undergoing orthodontic treatment. Am J Orthod Dentofacial Orthop. 1989; 96:47-53.

28. Bondemark L. Separation effect and perception of pain and discomfort from two types of orthodontic separators. World J Orthod. 2004; 5:172-6.

29. Furtsman L. Bernik S. Clinical consideration of the periodontium. Am J Orthod. 1972; 61:138-55.

30. Krishnan V. Orthodontic pain from causes to management: A review. Eur J Orthod. 2007; 29:170-9.

31. Cureton S, Bice RW. Comparison of three types of separators in adult patients. J Clin Orthod. 1997; 172-7. 